ARTICLE

DOI: $10.1038 / s 41467-017-00643-z$

OPEN

\title{
Observing the oxidation of platinum
}

Matthijs A. van Spronsen (1) ${ }^{1,3}$, Joost W.M. Frenken ${ }^{1,4} \&$ Irene M.N. Groot ${ }^{1,2}$

Despite its importance in oxidation catalysis, the active phase of Pt remains uncertain, even for the Pt(111) single-crystal surface. Here, using a ReactorSTM, the catalytically relevant structures are identified as two surface oxides, different from bulk $\alpha-\mathrm{PtO}_{2}$, previously observed. They are constructed from expanded oxide rows with a lattice constant close to that of $\alpha-\mathrm{PtO}_{2}$, either assembling into spoked wheels, $1-5$ bar $\mathrm{O}_{2}$, or closely packed in parallel lines, above 2.2 bar. Both are only ordered at elevated temperatures (400-500 K). The triangular oxide can also form on the square lattice of $\mathrm{Pt}(100)$. Under $\mathrm{NO}$ and $\mathrm{CO}$ oxidation conditions, similar features are observed. Furthermore, both oxides are unstable outside the $\mathrm{O}_{2}$ atmosphere, indicating the presence of active $\mathrm{O}$ atoms, crucial for oxidation catalysts.

\footnotetext{
${ }^{1}$ Huygens-Kamerlingh Onnes Laboratory, Leiden University, PO Box 9504, 2300 RA Leiden, The Netherlands. ${ }^{2}$ Leiden Institute of Chemistry, Leiden University, PO Box 9502, 2300 RA Leiden, The Netherlands. ${ }^{3}$ Present address: Harvard University, 12 Oxford street, Cambridge, MA 02138, USA. ${ }^{4}$ Present address: Advanced Research Center for Nanolithography (ARCNL), Science Park 110, 1098 XG Amsterdam, The Netherlands. Correspondence and requests for materials should be addressed to M.A.v.S. (email: spronsen@physics.leidenuniv.nl)
} 
P latinum serves as a major component in the automotive catalyst, which oxidizes $\mathrm{CO}$ and residual hydrocarbons to $\mathrm{CO}_{2}$. In addition, $\mathrm{NO}$ is oxidized when the catalyst is operating in lean burn, i.e., in excess oxygen. Research into the automotive catalyst remains highly relevant due to stricter emission regulations.

To improve catalysts by rational design, it is crucial to understand the structure and chemistry of a realistic catalyst under reaction conditions. However, this is often too difficult for a technical catalyst under chemical conditions and studies of model catalysts are vital. For the Pt-based automotive catalyst, the most essential model is the $\mathrm{Pt}(111)$ single-crystal surface. This surface has the lowest surface energy and is expected to form the largest facets in a real catalyst ${ }^{1}$.

The interaction of $\mathrm{O}_{2}$ with $\mathrm{Pt}(111)$ has been extensively studied under traditional surface science conditions, i.e., ultra-high vacuum (UHV). It was found that $\mathrm{O}_{2}$ binds molecularly below $160 \mathrm{~K}^{2,3}$, above which it dissociates readily and forms a $\mathrm{p}(2 \times 2)$-O chemisorption overlayer with a saturation coverage of $0.25 \mathrm{ML}$. High-temperature exposure ${ }^{4}$ or exposure to stronger oxidants, such as $\mathrm{NO}_{2}{ }^{5}, \mathrm{O}_{3}{ }^{6}$, and atomic oxygen ${ }^{7,8}$, was needed to create higher $\mathrm{O}$ coverages. This included a surface oxide consisting of one-dimensional (1D) oxidic rows, which were forming honeycomb-like superstructures ${ }^{5}$. Using these harsh conditions, even $\mathrm{PtO}_{2}$ could be created ${ }^{9}, 10$.

There is no guarantee that the structure of a catalyst observed in UHV is the same as the structure present under reaction conditions. This structure can only be elucidated when it is probed in situ, i.e., under high-pressure and elevated-temperature conditions. Two independent in situ surface X-ray diffraction (SXRD) studies showed the formation of bulk-like $\alpha-\mathrm{PtO}_{2}{ }^{11,12}$. These observations were contradicted by a near-ambient-pressure (NAP) X-ray photoelectron spectroscopy (XPS) study ${ }^{13}$, which showed the formation of a surface oxide at similar temperatures as in the SXRD experiments, but at lower pressures. This surface oxide was found to be an intermediate in the bulk oxidation of $\mathrm{Pt}$, which only started at much higher temperatures. In a recent NAP XPS study, it was found that prolonged exposure to oxidizing conditions was needed to form Pt oxide ${ }^{14}$.

The most important questions remain unanswered. What is the structure formed under catalytically relevant conditions? If it is an oxide, is this a surface or bulk oxide?
In this work, the oxidation of $\mathrm{Pt}(111)$ is probed with $\mathrm{O}_{2}$ pressures of $1-5$ bar and at $300-538 \mathrm{~K}$ using in situ scanning tunneling microscopy (STM). Interestingly, the formation of $\alpha-\mathrm{PtO}_{2}$ is not observed, instead two stable surface oxides form. The first has a structure in which equilateral triangles are arranged into spoked wheels. The lattice constant within the spokes is close to that of $\alpha-\mathrm{PtO}_{2}$. The second structure consist of a pattern of rows which are lifted from the surface and consisted of nearly half the amount of Pt atoms in the top layer. These surface oxide are not stable without the high $\mathrm{O}_{2}$ pressure indicating that the $\mathrm{O}$ atoms in these structures are very reactive, making them relevant for catalysis.

\section{Results}

Spoked-wheel superstructure. Upon exposing a Pt(111) surface to 1.0 bar $\mathrm{O}_{2}$ at $\sim 530 \mathrm{~K}$, triangular features appeared on the surface, assembling into spoked-wheel superstructures, see high-pressure STM images in Fig. 1. The average length of the edges was $2.2 \pm 0.1 \mathrm{~nm}$, corresponding to $7.9 \pm 0.4 \mathrm{Pt}(111)$-lattice constants. Domains of this superstructure extended tens of nanometers, as can be seen in Fig. 1a-c. These stable structures were still containing defects and disorder. This included translational defects, i.e., the shift of a row of spoked wheels, the incorporation of smaller triangles, and, incidentally, doubling/ tripling or missing of spokes. These defects are depicted in Supplementary Figs. 1 and 2 of Supplementary Note 1. During the growth phase, lasting 17-50 min, these defects were more abundant and also a transient, distorted-hexagonal structure was observed (Supplementary Fig. 3 in Supplementary Note 2).

Several images, such as Fig. 1c, d, show clear atomic resolution within the rows. The measured atomic periodicity in the rows was $0.30 \pm 0.01 \mathrm{~nm}$, which was significantly larger than the $\mathrm{Pt}(111)$ lattice constant of $0.278 \mathrm{~nm}$ and close to that of the UHV-stable surface oxide ${ }^{5}, \alpha-\mathrm{PtO}_{2}{ }^{15-19}$, and $\mathrm{PtO}^{15}, 19,20$. Based on this agreement, we consider this structure as a surface oxide comprised of 1D oxide rows. Most spokes consisted of eight atoms, including both endpoints, with very few being extended to nine or more. Given the spoke length of $2.2 \pm 0.1 \mathrm{~nm}$, this would lead to a lattice constant within the row of $0.31 \pm 0.01 \mathrm{~nm}$, close to, but slightly larger than the directly measured interatomic distance. As a consequence, the spoked-wheel structure had a unit
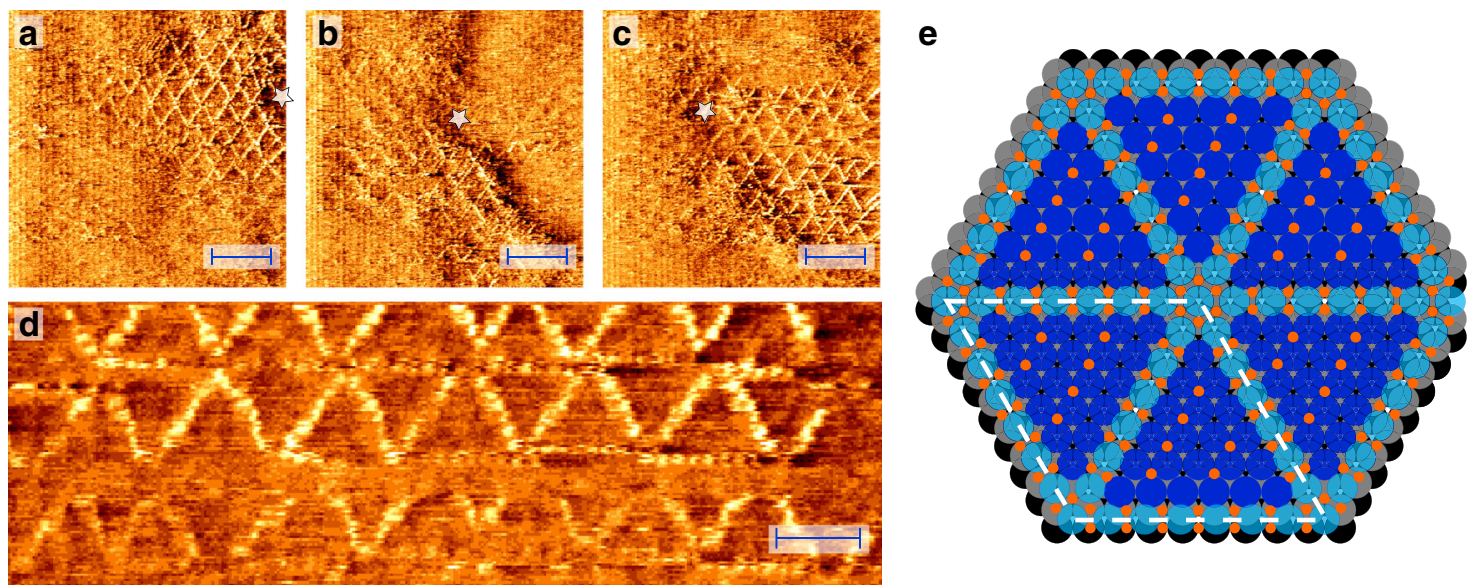

Fig. 1 Surface oxide on Pt(111). Surface oxide with spoked-wheel structure formed on Pt(111) while exposing it to 1 bar $\mathrm{O}_{2}$ at $529 \mathrm{~K}$. Three consecutive (a-c), large-scale STM images displaying extended domains. Field of view was slowly changing due to thermal drift (see white star as reference point); Enlarged detail (d), illustrating the atomic resolution within the spokes. Scale bars represent $4 \mathrm{~nm}(\mathbf{a}-\mathbf{c})$ and $2 \mathrm{~nm}$ (d). Proposed ball model (e) showing the spoked wheels within, but lifted from, the surface layer (oxidized Pt, light blue; $\mathrm{O}$, orange; Pt surface layers, blue, gray, and black). Positions of $\mathrm{O}$ atom were based on previous experiments and theory 5,26 

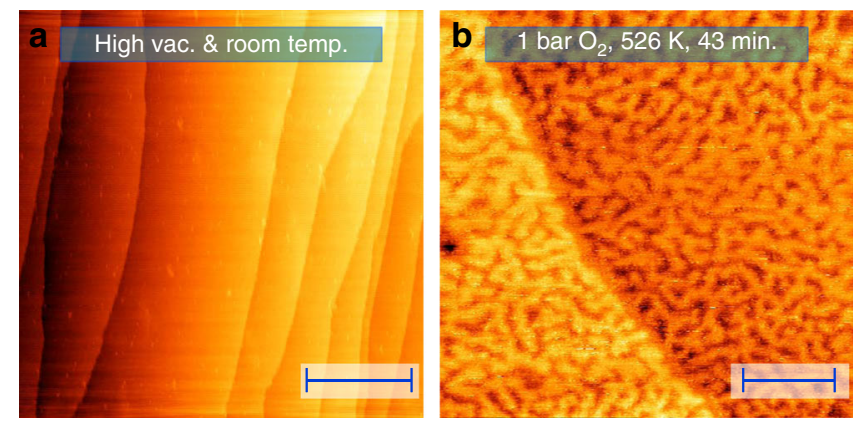

Fig. 2 Larger-scale structure of the surface oxide. STM images showing the change in large-scale morphology upon high-pressure $\mathrm{O}_{2}$ exposure. Freshly prepared $\mathrm{Pt}(111)$ surface (a) in the reactor (high vacuum at room temperature); stable, oxidized surface (b) at 1.0 bar $\mathrm{O}_{2}$ and $531 \mathrm{~K}$ after $43 \mathrm{~min}$ exposure to these conditions. Nonlinear filtering was applied to remove artifacts due to vibrational interference of the microscope. Scale bars represent $100 \mathrm{~nm}$ (a) and $20 \mathrm{~nm}$ (b)

cell close to $(8 \times 8)$ with the $\mathrm{Pt}$ atoms in the oxide rows showing an expansion of $\sim 8 / 7$.

This spoked-wheel superstructure was never identified before at the low pressures of most other $\mathrm{Pt}(111)$-oxidation studies, nor predicted by theory. Nevertheless, related surface oxides were found earlier, obtained in an artificial way, by oxidation with stronger oxidants. On $\mathrm{Pt}(111)$, one of these structures resembled the spoked-wheel structure and was formed by exposing the surface to an $\mathrm{O}$ beam $^{21}$. Another structure, with expanded chains assembling into honeycombs, was observed after exposure to $\mathrm{NO}_{2}$ at $450 \mathrm{~K}$ in vacuum ${ }^{5}$. In addition, related structures were proposed for $\mathrm{Pt}^{22,23}$ and (110)-type steps ${ }^{24,25}$. Although all these structures resemble some aspects of the spoked-wheel oxide, our experiments show that UHV oxidation with stronger oxidants does not guarantee to yield catalytically relevant structures.

Based on the STM measurements, the model in Fig. 1e is proposed. In this model, the $\mathrm{O}$ atoms in the chain are forming square planar units, surrounding a $\mathrm{Pt}$ atom. This geometry is based on the DFT calculations by Hawkins et al. ${ }^{26}$ and are structurally related to $\mathrm{PtO}$ and $\mathrm{Pt}_{3} \mathrm{O}_{4}$ with which they share the square planar $\mathrm{PtO}_{4}$ motifs. The spoked wheels are not on top of the surface but within the top layer, from where they are slightly lifted. This conjecture is based on the apparent height of the spokes that is much lower than a mono-atomic Pt step (Supplementary Table 1 in Supplementary Note 3) and is consistent with previous experiments ${ }^{5}$ and DFT calculations ${ }^{26-28}$. The $\mathrm{O}$ coverage of the proposed model is $0.75 \mathrm{ML}$ (Supplementary Note 4), three times more than generally obtained by $\mathrm{O}_{2}$ exposure in $\mathrm{UHV}^{2}, 3,29-31$.

The oxidation experiments were also performed using the square $\mathrm{Pt}(100)$ surface, which has a quasi-hexagonal reconstruction under UHV. Under oxidizing ( 1 bar $\mathrm{O}_{2}$ and $\sim 530 \mathrm{~K}$ ) conditions, the surface is predominantly covered with a network of rectangular islands, which consisted of rows with a double periodicity (Supplementary Fig. 4a). However, triangles were observed on several occasions (Supplementary Fig. 4b, c). This could indicate that the surface locally reconstructed back into a (quasi)hexagonal structure.

Large-scale formation of islands. Parallel to the formation of the spoked-wheel oxide, the surface roughened in a well-defined manner (compare Fig. 2a, b). The first shows the surface in the vacuum of the reactor prior to high-pressure exposure. Figure $2 \mathrm{~b}$ shows an in situ STM image of a surface region, exhibiting a mono-atomic step from the top left to the middle of the lower edge. Hence, the surface consisted of two terrace levels. Within each terrace, the surface showed a complicated network of wormshaped islands.

The islands divided each terrace in two levels. Figure $2 \mathrm{~b}$ suggests that the top level of the lower terrace was at the same height as the lower level of the upper terrace. In other words, the image indicates that the island structure divided each terrace over two height levels of the $\mathrm{Pt}(111)$ surface. This was supported by the depth of the voids in between the islands, which was $0.21 \pm 0.02 \mathrm{~nm}$, agreeing well with a mono-atomic $\mathrm{Pt}$ step. Therefore, we conclude that solid, flat terraces transformed into networks of mono-atomic-high, worm-shaped islands upon $\mathrm{O}_{2}$ exposure. Through the voids, the lower lying terrace became visible. This resulted in a two-level-terrace structure. We interpret this large-scale roughening as the consequence of the stress exerted by the oxide on the surface. This stress was relieved by forming the two-layer network. Interestingly, domains of the spoked wheels extended over several islands, including the voids in between.

Increasing $\mathrm{O}_{2}$ pressure. After a stable spoked-wheel structure was formed (1.0 bar, $530-538 \mathrm{~K}$ ), the $\mathrm{O}_{2}$ chemical potential was increased by gradually raising the $\mathrm{O}_{2}$ partial pressure to 5.0 bar. Starting at 2.2 bar $\mathrm{O}_{2}$, a new structure was observed (Fig. 3a). The image shows a pattern of parallel rows, which we will refer to as a lifted-row structure. Importantly, the spoked-wheel structure was still observed at all the experimentally probed $\mathrm{O}_{2}$ pressures. The domains of both structures were rather large and estimated to be above $100 \mathrm{~nm}$. Different rotational domains of the lifted-row structure were observed with an approximated size of, again, above $100 \mathrm{~nm}$. This was concluded from the absence of boundaries separating rotational domains.

Because the pressure was increasing, thermal drift was quite strong and highly nonlinear. The drift correction, based on the overlap between consecutive images, was difficult to perform accurately due to the, mainly, 1D character of the morphology and the presence of considerable dynamics. After correction, the row-to-row distance was $0.46 \pm 0.01 \mathrm{~nm}(0.44 \pm 0.01 \mathrm{~nm}$ before correction). This is close to $\sqrt{3} \times a$ ( $a=$ nearest $\mathrm{Pt}-\mathrm{Pt}$ distance), which equals $0.48 \mathrm{~nm}$, making this surface oxide commensurate with the $\mathrm{Pt}(111)$ substrate. Within the rows, the STM images revealed weak atomic features. However, these were not ordered enough to reliably determine a lattice constant. The measured height corrugation across the rows was very modest with an average value of $0.03 \pm 0.01 \mathrm{~nm}$, roughly a tenth of a monoatomic Pt step.

A model for the lifted-row oxide with similarly expanded oxide rows as the spoked-wheel oxide is depicted in Fig. $3 \mathrm{~b}$, c. The $\mathrm{O}$ coverage in this model is $0.88 \mathrm{ML}$ (Supplementary Note 4). The O atoms of neighboring rows can be disordered or ordered. Two ordered examples are shown in Fig. 3b, c. In the first (Fig. 3b), the lifted rows are 'in phase', minimizing the $\mathrm{O}-\mathrm{O}$ separation between adjacent stripes and is expected for attractive $\mathrm{O}-\mathrm{O}$ interaction. In the second example (Fig. 3c), the $\mathrm{O}-\mathrm{O}$ separation is maximized by shifting the phases between adjoining rows, expected for repulsive $\mathrm{O}-\mathrm{O}$ interactions. The unit cells for these two configurations are $(2 \times 8)$ Fig. $3 b(4 \times 8)$, Fig. $3 c$, respectively.

Two translational domains were observed, since either the odd or the even row could be lifted. They are indicated by the white and light blue lines in Fig. 3e (annotated replica of Fig. 3d). The dashed lines correspond to missing rows. In some cases, those missing lines were defects within a translational domain, while sometimes they were boundaries (so-called light domain walls) between two translational domains. In addition, point defects were observed, in which a single row switched domain. 

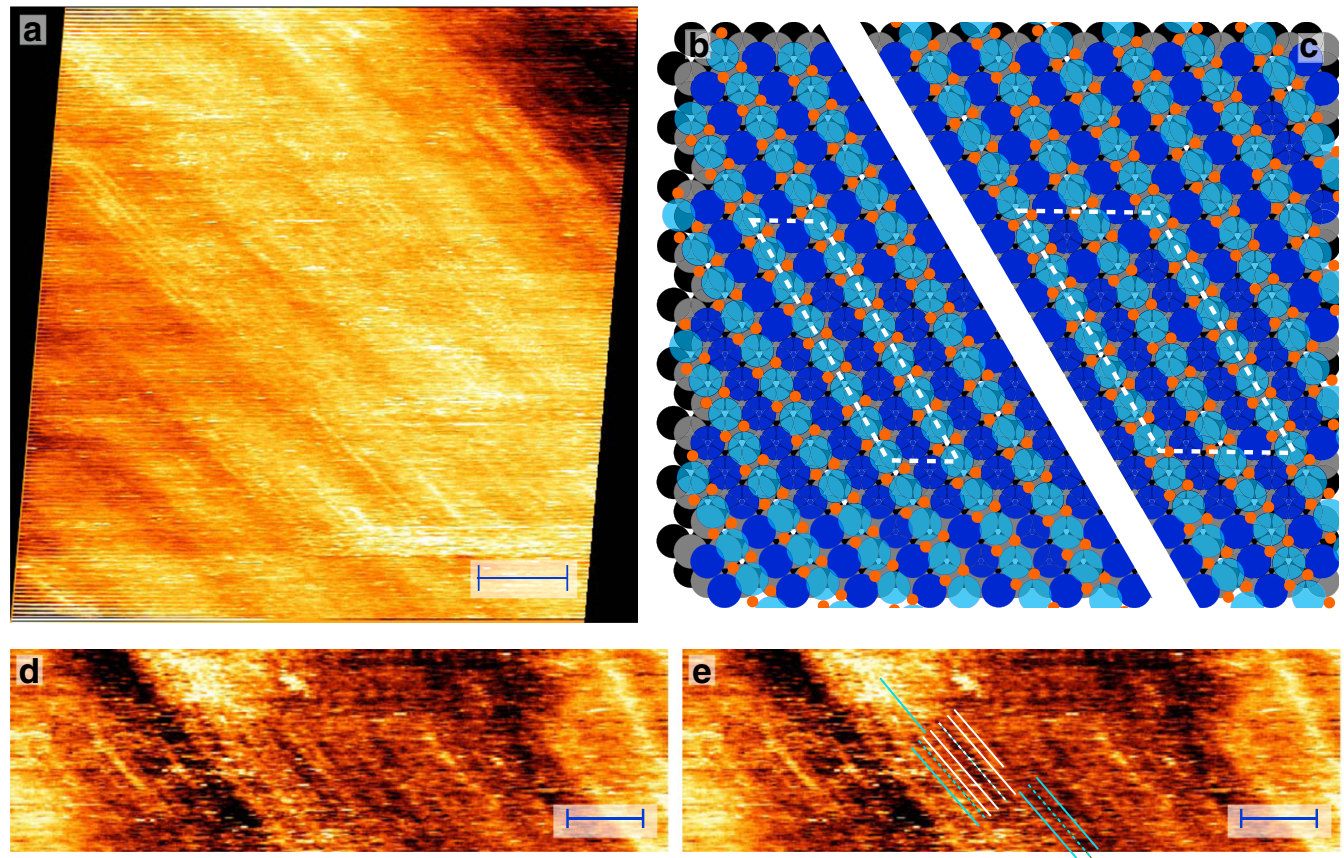

Fig. 3 Structures at higher $\mathrm{O}_{2}$ pressure. Lifted-row structure formed at higher $\mathrm{O}_{2}$ pressure (observed above 2.2 bar). STM image (a) recorded at $535 \mathrm{~K}$ in 3.8 bar $\mathrm{O}_{2}$, and $98 \mathrm{~min}$ in the experiment, while increasing the total pressure from 2.7 to 6.0 bar. The image is shown after drift correction and some nonlinear filtering to remove a few horizontal scan vibrations; Ball model of two examples of the lifted-row oxide in which the $\mathrm{O}$ atoms are ordered differently: lifted rows are in phase (b) resulting in straight lines of $\mathrm{O}$ atoms and the smallest $\mathrm{O}-\mathrm{O}$ separation; largest $\mathrm{O}-\mathrm{O}$ separation (c), due to shifting of adjacent rows by half a period. These structures have $\mathbf{a}(2 \times 8)$ and $\mathrm{c}(4 \times 8)$ unit cell, $\mathbf{b}$ and $\mathbf{c}$ respectively; Two replicas of an enlarged detail $(\mathbf{d}, \mathbf{e})$ of the lifted-row structure. Indicated lines (e) show several interesting features: missing rows, a light domain wall, and point defects. (Shown without drift correction but with a modest amount of nonlinear filtering to remove a few horizontal scan vibrations.) Scale bars represent $4 \mathrm{~nm}$ (a) and $3 \mathrm{~nm}$ (d, e)

Effect of temperature. Exposing the $\mathrm{Pt}(111)$ surface to 1.0 bar $\mathrm{O}_{2}$ at lower temperature $(291-338 \mathrm{~K})$, did not lead to large-scale ordered structures, but did lead to disordered structures. At these lower temperature conditions, thermodynamics predicts an even higher driving force to incorporate $\mathrm{O}$. This seems to contradict the observations and, hence, two possibilities remain. First, the disordered structures did contain more $\mathrm{O}$ than the ordered surface oxides. In this case, the structures would have to be disordered multilayers or contain subsurface O. Second, the formation of the ordered surface oxides was kinetically hindered. The latter notion is supported by the low-temperature observation of the basic structural elements, lifted rows and triangles, that are the building block for the ordered, higher temperature structures (Supplementary Fig. 5 in Supplementary Note 5). The limiting step can either be the rearrangement of the $\mathrm{Pt}$ atoms on a larger scale or the dissociation of $\mathrm{O}_{2}$. Similar observations were made after oxidation of $\mathrm{Pt}(110)$ at lower temperature ${ }^{22}$.

The main features observed at lower temperature were clusters with a diameter of $0.32 \pm 0.04 \mathrm{~nm}$. Their apparent height was much smaller than a mono-atomic step and was unaffected by changes in the sample bias. Therefore, we propose that these clusters were single $\mathrm{PtO}_{x}$ units, slightly lifted from the surface (Supplementary Table 2). It could be the building block of both the spoked-wheel and the lifted-row surface oxides. Similar clusters were previously observed ${ }^{5}$ and are possibly $\mathrm{PtO}_{3}$ units, as proposed by $\mathrm{DFT}^{26}$.

Vacuum stability of the surface oxides. The adsorption strength of the $\mathrm{O}$ atoms in the surface oxides was evaluated by evacuating the reactor after in situ growth at high-pressure, elevatedtemperature conditions. The decrease in pressure was rapid, reaching the $(\mathrm{U}) \mathrm{HV}$-regime within minutes, at which point the STM imaging was resumed (Supplementary Fig. 6 in
Supplementary Note 6). At the same time, heating of the surface was stopped, allowing the sample to cool down. After evacuation, no large-scale ordered structures were observed. In addition, the surface was very dynamical, leading to tip-induced restructuring and noisier STM images. In these experiments, no distinct structures, surface oxides nor chemisorption structures, were observed. This strongly suggested that the surface oxides were not fully stable upon evacuation, with oxygen (slowly) desorbing or reacting with residual gas.

Coverage estimate. XPS measurements in vacuum after highpressure, elevated-temperature exposure yielded a coverage estimate of $0.9 \pm 0.1 \mathrm{ML}$, after comparison to the saturated $p(2 \times 2)-\mathrm{O}$ chemisorption structure of $0.25 \mathrm{ML}^{2}, 3,29-31$ (Fig. 4). In addition, the binding energy was shifted from $528.5 \mathrm{eV}$, lower than typically observed for O(ads)/Pt (Supplementary Table 3), to $530.7 \mathrm{eV}$. The higher binding energy agreed well with the values found for oxidized Pt (Supplementary Table 4), although a clear trend in the literature is missing. A second XPS study (Supplementary Fig. 7a in Supplementary Note 7) focused on the decomposition of the surface oxide. The $\mathrm{O}$ coverage showed a constant, almost linear decrease with increasing temperature (Supplementary Fig. 7b). Although desorption started above $432 \mathrm{~K}$, some $\mathrm{O}$ was still present at $963 \mathrm{~K}$. This is either above or on the higher edge of $\mathrm{O}_{2}$ desorption from the $\mathrm{Pt}(111), \operatorname{Pt}(100)$, and $\mathrm{Pt}(110)$ surfaces ${ }^{2-6,8}, 22,32-36$. The increased stability could have resulted from the surface roughness ${ }^{37}$ or from subsurface $\mathrm{O}^{37,38}$

The binding energy was remarkably constant during decomposition of the oxide (Supplementary Fig. 7b). The absence of a binding energy shift can be explained by an area reduction of the surface oxide coexisting with bare, metallic Pt. Alternatively, it could have decomposed into a chemisorption structure, but only 
a

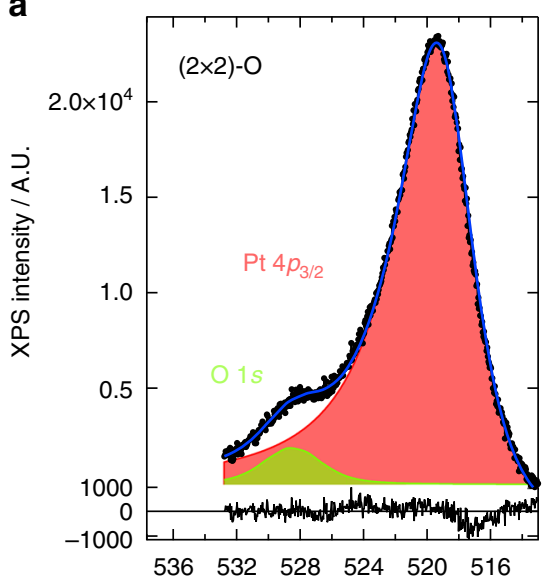

b

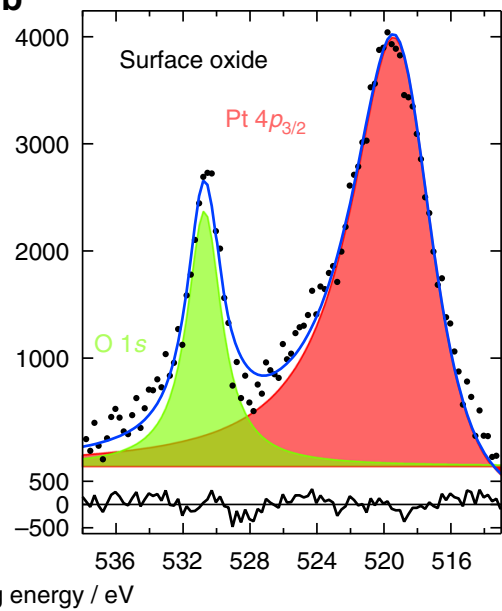

Fig. 4 XPS after oxidation. XP spectra collected after exposure of a clean Pt(111) sample to $400 \mathrm{~L} \mathrm{O}_{2}$ at room temperature (a) and to 1.0 bar $\mathrm{O}_{2}$ at $441-444$ $\mathrm{K}$ for $60 \mathrm{~min}$ (b). Spectra were fitted with a Doniach-Šunjić function convoluted with a Gaussian: O $1 \mathrm{~s}$ ( $g r e e n$ ) and Pt $4 p_{3 / 2}$ (pink). Lower panels show the fitting residual. To obtain a good fit, the $\mathrm{Pt} 4 p_{3 / 2}$ peak required considerable asymmetry in both spectra

if that was rather different from the $p(2 \times 2)$-O structure obtained in UHV, as the $\mathrm{O} 1 s$ binding energy did not shift from that of the surface oxide. As with the temperature stability, this can be related to oxygen-induced roughening and is supported by the work of Parkinson et al. ${ }^{7}$, in which a $(2 \times 2)$ diffraction pattern was observed on $\mathrm{Pt}(111)$ during oxide decomposition ${ }^{7}$. The $(2 \times 2)$ state had an $\mathrm{O} 1 \mathrm{~s}$ binding energy of $530.8 \mathrm{eV}$, very close to our reported values.

Stability with respect to $\alpha-\mathrm{PtO}_{2}$. In this study, $\alpha-\mathrm{PtO}_{2}$ was not observed, contradicting two SXRD studies on the same surface under similar conditions ${ }^{11,12}$. The conclusions in these studies were strongly based on the in-plane diffraction spots, which indicated a hexagonal overlayer with a lattice constant close to that of $\alpha-\mathrm{PtO}_{2}$. However, the spoked-wheel oxide would give similar in-plane hexagonal diffraction spots. Furthermore, both studies found a hexagonal unit cell parallel to the $\mathrm{Pt}(111)$ unit cell. However, $\alpha-\mathrm{PtO}_{2}$ would be expected to have a $30^{\circ}$ rotation with respect to the substrate ${ }^{1,9,10,39}$. On the other hand, X-rayinduced $\mathrm{O}_{3}$ formation could also explain the discrepancy ${ }^{12,40}$. Ozone was observed to strongly oxidize Pt even under UHV conditions ${ }^{6}$.

Calculated phase diagrams show that $\alpha-\mathrm{PtO}_{2}$ should be the stable phase under the experimental conditions $1,39,41$, suggesting that the surface oxides were only metastable with respect to $\alpha-\mathrm{PtO}_{2}$. In this case, there should be a strong kinetic limitation to form $\alpha-\mathrm{PtO}_{2}$, because the surface oxides are fully stable in our experiments. Since significant mobility was observed, any limitation should be related to $\mathrm{O}_{2}$ dissociation. In a NAP XPS study ${ }^{13}, \alpha-\mathrm{PtO}_{2}$ was observed only at $720 \mathrm{~K}$. More important than thermodynamic stability is the question of stability under catalytic conditions.

NO and CO oxidation conditions. The surface oxides observed in this study were unstable in vacuum. From the instability of the surface oxides in the evacuation experiments, it can be concluded that these oxides contain $\mathrm{O}$ atoms that are loosely bound and therefore highly reactive. For the spoked-wheel oxide, an interesting question to answer is which $\mathrm{O}$ atoms are more reactive. Are those the $\mathrm{O}$ atoms forming the $\mathrm{Pt}$ oxide stripes or are those the chemisorbed $\mathrm{O}$ atoms, which in turn can feel a strong repulsion from the $\mathrm{Pt}$ oxide spokes?
The spoked-wheel oxide developed similar roughness as that observed under $\mathrm{CO}$ oxidation conditions in an $\mathrm{O}_{2}$-rich flow ${ }^{42}$. Under these conditions, a higher reactivity was found for $\mathrm{CO}$ oxidation. Both the roughness and the higher reactivity phase can very well be explained by the formation of a single layer of the spoked-wheel oxide. In this case, $\mathrm{CO}$ can react with the $\mathrm{O}$ atoms of the surface oxide via a Mars-van Krevelen reaction mechanism. Similar large-scale structures were observed under NO oxidation conditions (Supplementary Fig. 8). Similar CO oxidation studies under reaction conditions for $\mathrm{Pt}$ and $\mathrm{Pd}$ model systems have recently been reviewed ${ }^{43,44}$ and the explanation of surface oxides as an active phase in oxidation reaction is in line with results for, e.g., the $\operatorname{Pt}(110)^{45-48}$ and $\operatorname{Pd}(100)^{49-51}$ surfaces.

\section{Discussion}

The STM images with the highest resolution were obtained with low bias voltages $(10-20 \mathrm{mV})$, implying that the surface oxides had no or a very small band gap. Although conflicting with observed band gaps of the surface oxide and oxide clusters on $\mathrm{Pt}$ (110), a small or lacking band gap is not fully unpredictable. Pt oxides have relatively small band gaps. For example, experimental values for crystalline $\mathrm{PtO}_{2}$ were $1.8^{52}$ and $2.5 \mathrm{eV}^{53}$ and for $\mathrm{PtO}$ it is not fully clear whether it even has a band gap ${ }^{19,20,54-56}$. Furthermore, structural disorder lowers the band gap ${ }^{57,58}$.

The observed 1D oxide chains are structurally more related to the lower band-gap oxide, PtO. In addition, the Pt atoms in the 1D oxide chains are closely spaced with those not directly involved in the surface oxide and, possibly, these two kinds of Pt atoms can sufficiently bind and eliminate the band gap. Alternatively, the absence of a band gap can be rationalized by a fractional oxidation state. Oxidation states of $\mathrm{Pt}$ oxides deviate strongly from the formal oxidation states of $\mathrm{Pt}^{2+}$ and $\mathrm{Pt}^{4+}$, having significant covalent character $24,26,55,56,59,60$, which can also be expected for the surface oxides. This fractional oxidation state results in partial occupation of the highest $d$-orbital. Finally, the abundantly present defects in these surface oxides can also explain the lack of band gap.

Exposing the $\mathrm{Pt}(111)$ model catalyst to oxidizing atmospheres under realistic catalytic conditions $\left(300-538 \mathrm{~K}, 1-5\right.$ bar $\left.\mathrm{O}_{2}\right)$ leads to the formation of two different single-layer surface oxides, the spoked-wheel and the lifted-row oxide. We propose that both consist of expanded, Pt oxide rows. Ordered surface oxides were solely observed under both high pressure and elevated 
temperature, proving the absolute necessity of in situ measurements. Moreover, these surface oxides were not stable without the presence of the high $\mathrm{O}_{2}$ pressure. Additional experiments indicated that these surface oxides are important for $\mathrm{CO}$ and $\mathrm{NO}$ oxidation. Furthermore, similar structures are formed on $\mathrm{Pt}(100)$.

To translate the results obtained on a $\mathrm{Pt}(111)$ model catalyst to real, complex catalysts, one important point is the effect of nano-confinement. This confinement is a direct consequence of the use of nanoparticles as catalysts. For the smallest particles, their (111) facets will be on the same order of size as the spoked wheels. This could make the spoked-wheel oxide less stable. On the other hand, nanoparticles may have less difficulty to relieve the strain induced by the surface oxide than extended single crystals. To clarify this point, in situ experiments yielding atomic resolution on the facets of particles, possibly aided by DFT calculations, will be needed.

\section{Methods}

ReactorSTM. All experiments were performed in a ReactorSTM ${ }^{61,62}$, which is a UHV system housing a small-volume $(0.5 \mathrm{ml})$ flow-cell reactor integrated with an STM. The design is such that all delicate STM parts are outside the reactor and not exposed to gases or to high temperatures. Only the polished side of the sample and the tip with its sliding tip holder are inside the reactor. To seal the high-pressure reactor from the UHV chamber, a fluoroelastomer seal ${ }^{63}$ is used. In this way, UHV conditions are maintained in the surrounding chamber, even when the reactor pressure reaches 6 bar. The fluoroelastomer limits the temperature of the high-pressure experiment to $600 \mathrm{~K}$. The temperature is measured with a K-type thermocouple. The sample is heated with a filament placed on the vacuum side of the sample. In addition, the system houses equipment for low-energy electron diffraction, Auger electron spectroscopy, and XPS, which can be employed before and after high-pressure exposure of the sample.

Single-crystal sample preparation. The platinum single crystal (Czochralskigrown, purity of $5 \mathrm{~N}^{64}$ ) was polished to the (111) plane within $0.1^{\circ}$. After polishing, it was cleaned by $\mathrm{Ar}^{+}$sputtering $(\sim 20 \mathrm{~min}$, beam energy of $1.0 \mathrm{keV}$, and sample current of $3-4 \mu \mathrm{A})$ and annealing both in $\mathrm{O}_{2}\left(\sim 2 \mathrm{~min}\right.$ at $948 \mathrm{~K}$ in $\left.1 \times 10^{-7} \mathrm{mbar} \mathrm{O}_{2}\right)$ and in UHV (at $1130 \mathrm{~K}$ for $\sim 10 \mathrm{~min}$ ). At least $60-70$ of these cycles were performed before starting the first experiment and around 5 cycles were completed between consecutive experiments. The preparation method was routinely checked with both LEED (Supplementary Fig. 9) (Omicron SPECTALEED, 4 grid) and AES (Omicron SPECTALEED, retarding field analyzer)

Gases. The gases $\left(\mathrm{O}_{2}\right.$ : Praxair 5.0N and $\mathrm{CK} 4.5 \mathrm{~N}$ and Ar: Linde $6.0 \mathrm{~N}$, Westfalen $5.0 \mathrm{~N}$, Praxair $5.0 \mathrm{~N}$ ) were used without further purification. Unless specified otherwise, all experiments were performed at a total normal flow, i.e., the flow at a pressure of $1.013 \mathrm{bar}$ at $273 \mathrm{~K}$, of $10 \mathrm{ml} / \mathrm{min}$ with $83.3 \% \mathrm{O}_{2}$ and $16.7 \% \mathrm{Ar}$.

STM measurements. STM measurements were performed with cut PtIr tips and in constant-current mode using a video-rate STM controller ${ }^{65,66}$. Both planar and linear line-by-line background subtractions were employed. In order to emphasize local height variations, several images are presented in differentiated form with the color indicating the local slope measured from left to right. To calibrate the piezoelectric scan element, atomically resolved $\mathrm{Au}(111)$ STM images were used. These images were recorded with a closed reactor, with a seal in place at room temperature, in vacuum. This resulted in a calibration with a standard deviation of $1.5 \%$

XPS measurements. All XP spectra were collected in UHV, but without exposing the sample to air, using $\mathrm{Al} \mathrm{K} \alpha$ radiation (VG XR3E2, non-monochromatic). Emitted photoelectons were detected with a hemispherical analyzer (VG Clam2/ $1 \mathrm{VU}, 100 \mathrm{~mm}$ radius) equipped with a collimator aperture to bring the spot size down to $\sim 8 \mathrm{~mm}$. The detector was operated with a slit size of $4.0 \mathrm{~mm}$ and the electrostatic lenses at 3:1 mode, reducing the spot size further to $\sim 1.3 \mathrm{~mm}$. The sample was facing the detector, with the X-ray beam impinging under an angle of $55^{\circ}$ with respect to the surface normal. To ensure that the inspected area coincided with that exposed in the reactor, the ring-shaped imprint of the fluoroelastomer was used, on which a strong F peak could be discerned. Importantly, the center of the sample did not show any $\mathrm{F}$ contamination before or after the high-pressure experiments. The energy range of interest, around the $\mathrm{O} 1 s$ and $\mathrm{Pt} 4 p_{3 / 2}$ peaks, was probed with a constant analyzer energy $(25 \mathrm{~V})$. The binding energies were calibrated against the known energy of the Pt $4 p_{3 / 2}$ peak of $519.5(3) \mathrm{eV}^{67}$. After calibration, the spectra were corrected by subtracting a linear background. The XP peaks were fitted with a Doniach-Šunjić function ${ }^{68}$ convoluted with a Gaussian, requiring the following fitting parameters: binding energy, intensity, Lorentzian line width, Gaussian line width, and asymmetry factor. For the temperature- dependent experiments, a simpler procedure was followed, consisting of subtraction of a constant background and normalization to the maximum $\mathrm{Pt} 4 \mathrm{p}_{3 / 2}$ intensity. This was followed by fitting the $\mathrm{O} 1 s$ peaks with a Gaussian function.

Data availability. The data that support the findings of this study are available from the corresponding author upon reasonable request.

Received: 19 April 2017 Accepted: 17 July 2017

Published online: 05 September 2017

\section{References}

1. Seriani, N. \& Mittendorfer, F. Platinum-group and noble metals under oxidizing conditions. J. Phys. Condens. Matter 20, 184023 (2008).

2. Gland, J. L. Molecular and atomic adsorption of oxygen on the $\mathrm{Pt}(111)$ and $\mathrm{Pt}$ (S)-12(111) $\times(111)$ surfaces. Surf. Sci. 93, 487-514 (1980).

3. Steininger, H., Lehwald, S. \& Ibach, H. Adsorption of oxygen on Pt(111). Surf. Sci. 123, 1-17 (1982)

4. Derry, G. N. \& Ross, P. N. High coverage states of oxygen adsorbed on Pt(100) and $\operatorname{Pt}(111)$ surfaces. Surf. Sci. 140, 165-180 (1984).

5. Devarajan, S. P., Hinojosa, J. A. Jr \& Weaver, J. F. STM study of high-coverage structures of atomic oxygen on $\operatorname{Pt}\left(\begin{array}{lll}1 & 1 & 1\end{array}\right): \mathrm{p}(2 \times 1)$ and $\mathrm{Pt}$ oxide chain structures. Surf. Sci. 602, 3116-3124 (2008).

6. Saliba, N. A., Tsai, Y.-L., Panja, C. \& Koel, B. E. Oxidation of Pt(111) by ozone $\left(\mathrm{O}_{3}\right)$ under UHV conditions. Surf. Sci. 419, 79-88 (1999).

7. Parkinson, C. R., Walker, M. \& McConville, C. F. Reaction of atomic oxygen with a $\mathrm{Pt}(111)$ surface: chemical and structural determination using XPS, CAICISS and LEED. Surf. Sci. 545, 19-33 (2003).

8. Weaver, J. F., Chen, J.-J. \& Gerrard, A. L. Oxidation of $\mathrm{Pt}(111)$ by gas-phase oxygen atoms. Surf. Sci. 592, 83-103 (2005).

9. Salmerón, M., Brewer, L. \& Somorjai, G. A. The structure and stability of surface platinum oxide and of oxides of other noble metals. Surf. Sci. 112, 207-228 (1981).

10. Krasnikov, S. A. et al. Self-limited growth of triangular $\mathrm{PtO}_{2}$ nanoclusters on the Pt(111) surface. Nanotechnology. 21, 335301 (2010).

11. Ellinger, C., Stierle, A., Robinson, I. K., Nefedov, A. \& Dosch, H. Atmospheric pressure oxidation of Pt(111). J. Phys. Condens. Matter 20, 184013 (2008).

12. Ackermann, M. D. Operando SXRD: a New View on Catalysis. Ph.D. thesis, (Leiden University, 2007).

13. Miller, D. J. et al. Oxidation of $\mathrm{Pt}(111)$ under near-ambient conditions. Phys. Rev. Lett. 107, 195502 (2011).

14. Fantauzzi, D. et al. Growth of stable surface oxides on $\mathrm{Pt}(111)$ at near-ambient pressures. Angew. Chem. Int. Ed. 56, 2594-2598 (2017).

15. Moore, W. J. \& Pauling, L. The crystal structures of the tetragonal monoxides of lead, tin palladium, and platinum. J. Am. Chem. Soc. 63, 1392-1394 (1941).

16. Galloni, E. E. \& Busch, R. H. The structure of platinum oxides. J. Chem. Phys. 20, 198-199 (1952)

17. Shishakov, N. A., Asanov, U. \& Andrushchenko, N. K. Simple method of preparing pure platinum dioxide. Russ. Chem. Bull. 9, 350-351 (1960).

18. Muller, O. \& Roy, R. Formation and stability of the platinum and rhodium oxides at high oxygen pressures and the structure of the $\mathrm{Pt}_{3} \mathrm{O}_{4}, \beta-\mathrm{PtO}_{2}$ and $\mathrm{RhO}_{2}$. J. Less Common Metals 16, 129-146 (1968).

19. McBride, J. R., Graham, G. W., Peters, C. R. \& Weber, W. H. Growth and characterization of reactively sputtered thin-film platinum oxides. J. Appl. Phys. 69, 1596-1604 (1991).

20. Westwood, W. D. \& Bennewitz, C. D. Formation of PtO films by reactive sputtering. J. Appl. Phys. 45, 2313-2315 (1974).

21. Weaver, J. F. Surface chemistry of late transition metal oxides. Chem. Rev. 113, 4164-4215 (2013).

22. Li, W. X. et al. Oxidation of Pt(110). Phys. Rev. Lett. 93, 146104 (2004).

23. Pedersen, T. M., Li, W. X. \& Hammer, B. Structure and activity of oxidized Pt (110) and $\alpha-\mathrm{PtO}_{2}$. Phys. Chem. Chem. Phys. 8, 1566-1574 (2006).

24. Wang, J. G. et al. One-dimensional $\mathrm{PtO}_{2}$ at Pt Steps: formation and reaction with CO. Phys. Rev. Lett. 95, 256102 (2005).

25. Bandlow, J. et al. Oxidation of stepped $\mathrm{Pt}(111)$ studied by X-Ray photoelectron spectroscopy and density functional theory. Phys. Rev. B 83, 174107 (2011).

26. Hawkins, J. M., Weaver, J. F. \& Asthagiri, A. Density functional theory study of the initial oxidation of the Pt(111) surface. Phys. Rev. B 79, 125434 (2009).

27. Holby, E. F., Greeley, J. \& Morgan, D. Thermodynamics and hysteresis of oxide formation and removal on platinum (111) surfaces. J. Phys. Chem. C 116 9942-9946 (2012).

28. Fantauzzi, D., Mueller, J. E., Sabo, L., Van Duin, A. C. T. \& Jacob, T. Surface buckling and subsurface oxygen: Atomistic insights into the surface oxidation of Pt (111). Chemphyschem. 16, 2797-2802 (2015). 
29. Mortensen, K., Klink, C., Jensen, F., Besenbacher, F. \& Stensgaard, I. Adsorption position of oxygen on the Pt(111) surface. Surf. Sci. 220, L701-L708 (1989).

30. Starke, U. et al. A low-energy electron diffraction study of oxygen, water and ice adsorption on Pt(111). Surf. Sci. 287-288, 432-437 (1993).

31. Materer, N. et al. Reliability of detailed LEED structural analyses: $\mathrm{Pt}(111)$ and $\mathrm{Pt}(111)-\mathrm{p}(2 \times 2)-$ O. Surf. Sci. 325, 207-222 (1995).

32. Parker, D. H., Bartram, M. E. \& Koel, B. E. Study of high coverages of atomic oxygen on the Pt(111) surface. Surf. Sci. 217, 489-510 (1989).

33. Artsyukhovich, A. N., Ukraintsev, V. A. \& Harrison, I. low temperature sticking and desorption dynamics of oxygen on Pt(111). Surf. Sci. 347, 303-318 (1996).

34. Jerdev, D. I., Kim, J., Batzill, M. \& Koel, B. E. Evidence for slow oxygen exchange between multiple adsorption sites at high oxygen coverages on $\mathrm{Pt}$ (111). Surf. Sci. 498, L91-L96 (2002).

35. Shumbera, R. B., Kan, H. H. \& Weaver, J. F. Oxidation of Pt(100)-hex-R0. $7^{\circ}$ by gas-phase oxygen atoms. Surf. Sci. 601, 235-246 (2007).

36. Shumbera, R. B., Kan, H. H. \& Weaver, J. F. The transition from surface to bulk oxide growth on $\mathrm{Pt}(100)$ : Precursor-mediated kinetics. Surf. Sci. 601, 4809-4816 (2007).

37. Held, G., Jones, L. B., Seddon, E. A. \& King, D. A. Effect of oxygen adsorption on the chiral Pt $\{531\}$ surface. J. Phys. Chem. B. 109, 6159-6163 (2005).

38. Bashlakov, D. L., Juurlink, L. B. F., Koper, M. T. M. \& Yanson, A. I. Subsurface oxygen on $\mathrm{Pt}(111)$ and its reactivity for $\mathrm{CO}$ oxidation. Catal. Lett. 142, 1-6 (2012).

39. Seriani, N., Pompe, W. \& Ciacchi, L. C. Catalytic oxidation activity of $\mathrm{Pt}_{3} \mathrm{O}_{4}$ surfaces and thin films. J. Phys. Chem. B. 110, 14860-14869 (2006).

40. Butcher, D. R. et al. In situ oxidation study of $\mathrm{Pt}(110)$ and its interaction with CO. J. Am. Chem. Soc. 133, 20319-20325 (2011).

41. Zhu, T., Sun, S. G., Van Santen, R. A. \& Hensen, E. J. M. Reconstruction of clean and oxygen-covered $\mathrm{Pt}(110)$ surfaces. J. Phys. Chem. C 117, 11251-11257 (2013).

42. Bobaru, S. C. High-Pressure STM Studies of Oxidation Catalysis. Ph.D. thesis, (Leiden University, 2006).

43. Frenken, J. W. M. \& Groot, I. M. N. in Operando Research in Heterogeneous Catalysis, 1-30 (Springer, 2017).

44. Van Spronsen, M. A., Frenken, J. W. M. \& Groot, I. M. N. Surface science under reaction conditions: $\mathrm{CO}$ oxidation on $\mathrm{Pt}$ and $\mathrm{Pd}$ model catalysts. Chem. Soc. Rev. 46, 4347-4374 (2017).

45. Hendriksen, B. L. M. \& Frenken, J. W. M. CO oxidation on Pt(110): scanning tunneling microscopy inside a high-pressure flow reactor. Phys. Rev. Lett. 89, 046101 (2002)

46. Ackermann, M. D. et al. Structure and reactivity of surface oxides on $\operatorname{Pt}(110)$ during catalytic CO oxidation. Phys. Rev. Lett. 95, 255505 (2005).

47. Van Spronsen, M. A., Van Baarle, G. J. C., Herbschleb, C. T., Frenken, J. W. M. \& Groot, I. M. N. High-pressure operando STM studies giving insight in CO oxidation and NO reduction over Pt(1 110$)$. Catal. Today 244, 85-95 (2015).

48. Hendriksen, B. L. M., Bobaru, S. C. \& Frenken, J. W. M. Oscillatory CO oxidation on $\mathrm{Pd}(100)$ studied with in situ scanning tunneling microscopy. Surf. Sci. 552, 229-242 (2004)

50. Van Rijn, R. et al. Surface structure and reactivity of Pd (100) during CO oxidation near ambient pressures. Phys. Chem. Chem. Phys. 13, 13167-13171 (2011).

51. Onderwaater, W. G. et al. Oxidation of CO on Pd (100): On the structural evolution of the PdO layer during the self sustained oscillation regime. Catal. Struct. React. 3, 89-94 (2017).

52. Zhensheng, J. et al. Catalytic behavior of nanoparticle $\alpha-\mathrm{PtO}_{2}$ for ethanol oxidation. J. Mol. Catal. A: Chem 191, 61-66 (2003).

53. Canart-Martin, M. C., Delrue, J. P., Laude, L. D. \& Wautelet, M. Electronic structure and reduction processes in $\mathrm{PtO}_{x}$ films. Chem. Phys. 48, 283-288 (1980).

54. Abe, Y., Kawamura, M. \& Sasaki, K. Preparation of PtO and $\alpha-\mathrm{PtO}_{2}$ thin films by reactive sputtering and their electrical properties. Jpn. J. Appl. Phys. 38, 2092-2096 (1999)

55. Uddin, J., Peralta, J. E. \& Scuseria, G. E. Density functional theory study of bulk platinum monoxide. Phys. Rev. B 71, 155112 (2005).

56. Kaewmaraya, T., Ramzan, M., Sun, W., Sagynbaeva, M. \& Ahuja, R. Atomistic study of promising catalyst and electrode material for memory capacitors: platinum oxides. Comp. Mater. Sci. 79, 804-810 (2013).

57. Aita, C. R. Optical behavior of sputter-deposited platinum-oxide films. J. Appl. Phys. 58, 3169-3173 (1985)
58. Neff, H. et al. Structural, optical, and electronic properties of magnetronsputtered platinum oxide films. J. Appl. Phys. 79, 7672-7675 (1996).

59. Xu, Y., Shelton, W. A. \& Schneider, W. F. Effect of particle size on the oxidizability of platinum clusters. J. Phys. Chem. A. 110, 5839-5846 (2006).

60. Seriani, N., Jin, Z., Pompe, W. \& Ciacchi, L. C. Density functional theory study of platinum oxides: From infinite crystals to nanoscopic particles. Phys. Rev. $B$ 76, 155421 (2007).

61. Herbschleb, C. T. et al. The ReactorSTM: atomically resolved scanning tunneling microscopy under high-pressure, high-temperature catalytic reaction conditions. Rev. Sci. Instrum. 85, 083703 (2014).

62. Roobol, S. B. et al. The ReactorAFM: non-contact atomic force microscope operating under high-pressure and high-temperature catalytic conditions. Rev. Sci. Instrum. 86, 033706 (2015).

63. DuPont ${ }^{\text {tw }}$ Kalrez ${ }^{\circledast}$ Spectrum $^{\text {twx }} 7075-$ Technical Information. www.dupont.com/ content/dam/dupont/products-and-services/plastics-polymers-and-resins/ parts-and-shapes/kalrez/documents/Kalrez (2012).

64. Surface Preparation Laboratory. www.spl.eu (2015).

65. Rost, M. J. et al. Scanning probe microscopes go video rate and beyond. Rev. Sci. Instrum. 76, 053710 (2005).

66. Leiden Probe Microscopy BV. www.leidenprobemicroscopy.com (2015).

67. Nyholm, R., Berndtsson, A. \& Martensson, N. Core level binding energies for the elements Hf to Bi $(Z=72-83)$. J. Phys. C 13, L1091-L1096 (1980).

68. Doniach, S. \& Šunjić, M. Many-electron singularity in X-ray photoemission and X-ray line spectra from metals. J. Phys. C 3, 285-291 (1970).

\section{Acknowledgements}

P.C. van der Tuijn and M. Bergman of the Department of Fine Mechanics of the Leiden Institute of Physics, Leiden University are gratefully acknowledged for their excellent technical support. In addition, the experimental assistance of Dr M.J. Rost and Dr J.W. Bakker was strongly appreciated. This work is supported by NanoNextNL, a micro and nanotechnology consortium of the Government of the Netherlands and 130 partners. I. M.N.G. acknowledges the Dutch Organization for Scientific Research for her Veni fellowship.

\section{Author contributions}

M.A.v.S. designed and performed the experiments and analyzed the data. J.W.M.F. and I.M.N.G. supervised the experiments. All authors have discussed the scientific results and have written the paper.

\section{Additional information}

Supplementary Information accompanies this paper at doi:10.1038/s41467-017-00643-Z.

Competing interests: The authors declare no competing financial interests.

Reprints and permission information is available online at http://npg.nature.com/ reprintsandpermissions/

Publisher's note: Springer Nature remains neutral with regard to jurisdictional claims in published maps and institutional affiliations.

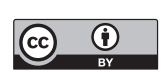

Open Access This article is licensed under a Creative Commons Attribution 4.0 International License, which permits use, sharing, adaptation, distribution and reproduction in any medium or format, as long as you give appropriate credit to the original author(s) and the source, provide a link to the Creative Commons license, and indicate if changes were made. The images or other third party material in this article are included in the article's Creative Commons license, unless indicated otherwise in a credit line to the material. If material is not included in the article's Creative Commons license and your intended use is not permitted by statutory regulation or exceeds the permitted use, you will need to obtain permission directly from the copyright holder. To view a copy of this license, visit http://creativecommons.org/ licenses/by/4.0/

(C) The Author(s) 2017 